\title{
Atypical Femoral Fractures in Patients Taking Longterm Alendronate
}

MANISHA MULGUND, MD, Rheumatology Fellow; KAREN A. BEATTIE, PhD, Assistant Professor, Department of Medicine; RAHUL ANASPURE, MD, Musculoskeletal Radiology Fellow, Department of Radiology; MARK MATSOS, MD, Assistant Professor; AMEEN PATEL, MD, Professor; JONATHAN D. ADACHI, MD, Professor, Department of Medicine, McMaster University, Hamilton, Ontario, Canada. Address correspondence to Dr. K. Beattie, 501-25 Charlton Ave. East, Hamilton, Ontario L8N 1Y2, Canada. E-mail: karen.beattie@ camris.ca. J Rheumatol 2011:38:2686-7; doi:10.3899/jrheum110725

Although fragility fractures in the subtrochanteric/femoral shaft (ST/FS) regions are not frequently reported in osteoporotic individuals, a potential link between prolonged bisphosphonate use and low-energy femoral fractures resulting from suppression of bone turnover, accumulation of microdamage, and failure of aging collagen ${ }^{1}$. Such fractures have been characterized by a specific radiographic appearance ${ }^{2}$, a simple transverse or oblique fracture, beaking of the cortex, and diffuse cortical thickening 3 ,4,5. We performed retrospective chart reviews on 10 women with ST/FS fractures (mean age 69.2, SD 8.9, yrs), all of whom were undergoing longterm alendronate therapy (mean 8.3, SD 2.4, yrs). Two patients had bilateral fractures. All fractures met the American Society for Bone and Mineral Research criteria for atypical femoral fractures $^{2}$. Five women had thigh pain prior to fracture, 4 had a previous fragility fracture, and 5 of the 8 patients that underwent investigations on the contralateral femur had stress reactions (Figure 1). All fractures were transverse or short oblique in configuration, without comminution, and showed diffuse or focal cortical thickening. Radiographs were analyzed by a musculoskeletal radiologist to quantify total (medial + lateral) cortical thickness at a fixed location (Figure 2). The mean ratio of cortical thickness normalized to bone diameter to correct for magnification was 0.50 (SD 0.09). It is unclear if these atypical fractures are related to altered bone physiology or excessive stresses. Cortical thickening may be a sequela of gradual periosteal and endosteal new bone formation, secondary to cortical fractures and cumulative stress reaction. Future studies quantifying cortical thickness in individuals without femoral fractures would provide reference values for comparison.

\section{REFERENCES}

1. Lenart BA, Neviaser AS, Lyman S, Chang CC, Edobor-Osula F, Steele B, et al. Association of low-energy femoral fractures with prolonged bisphosphonate use: a case control study. Osteoporos Int 2009;20:1353-62.

2. Shane E, Burr D, Ebeling PR, Abrahamsen B, Adler RA, Brown $\mathrm{TD}$, et al. Atypical subtrochanteric and diaphyseal femoral
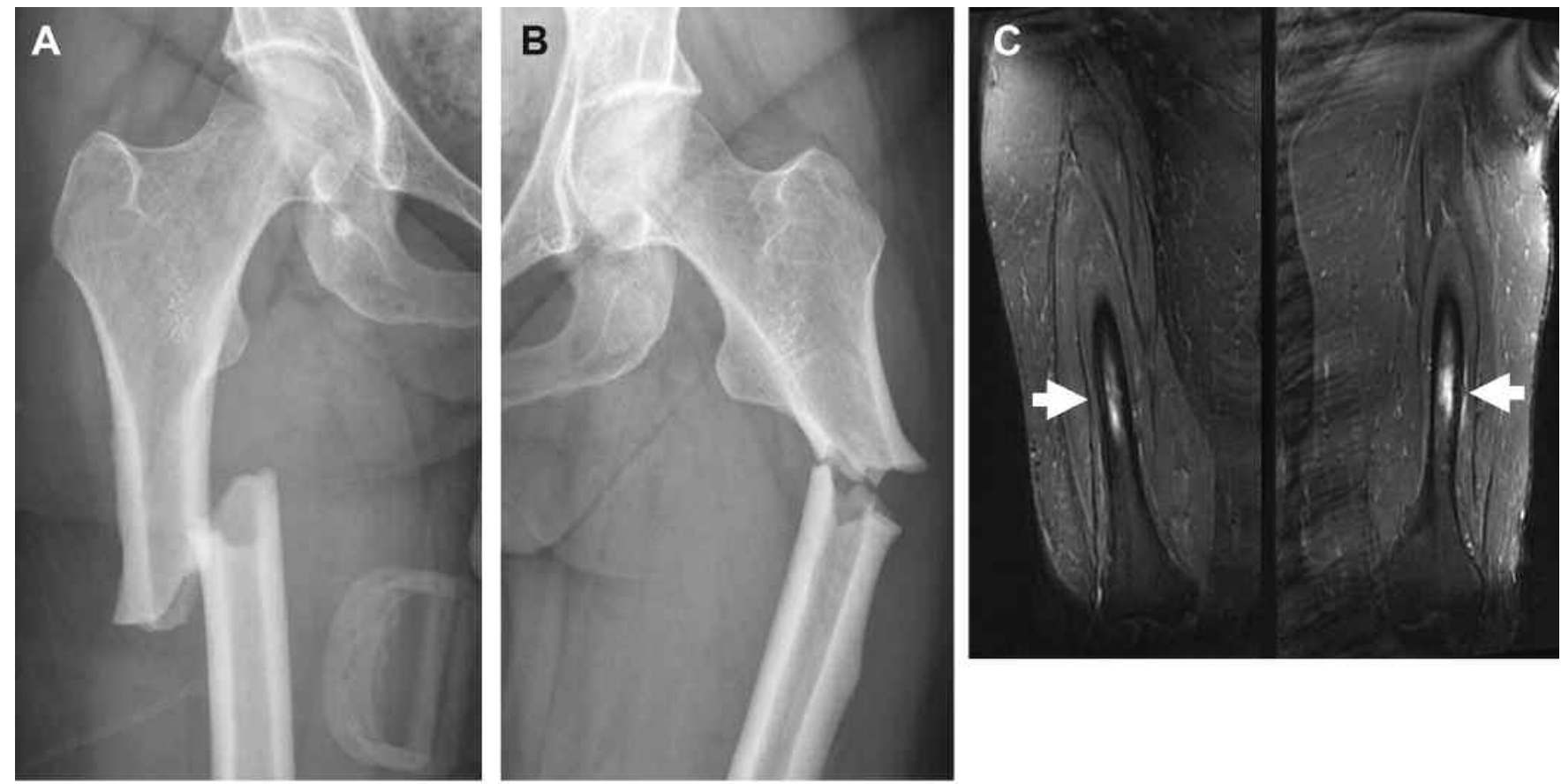

Figure 1. Radiographs of atypical subtrochanteric femoral fractures (A and B) with apparent cortical thickening, and magnetic resonance image scans (C) of the left and right femurs depicting bilateral bone marrow edema in a patient with bilateral fractures. 


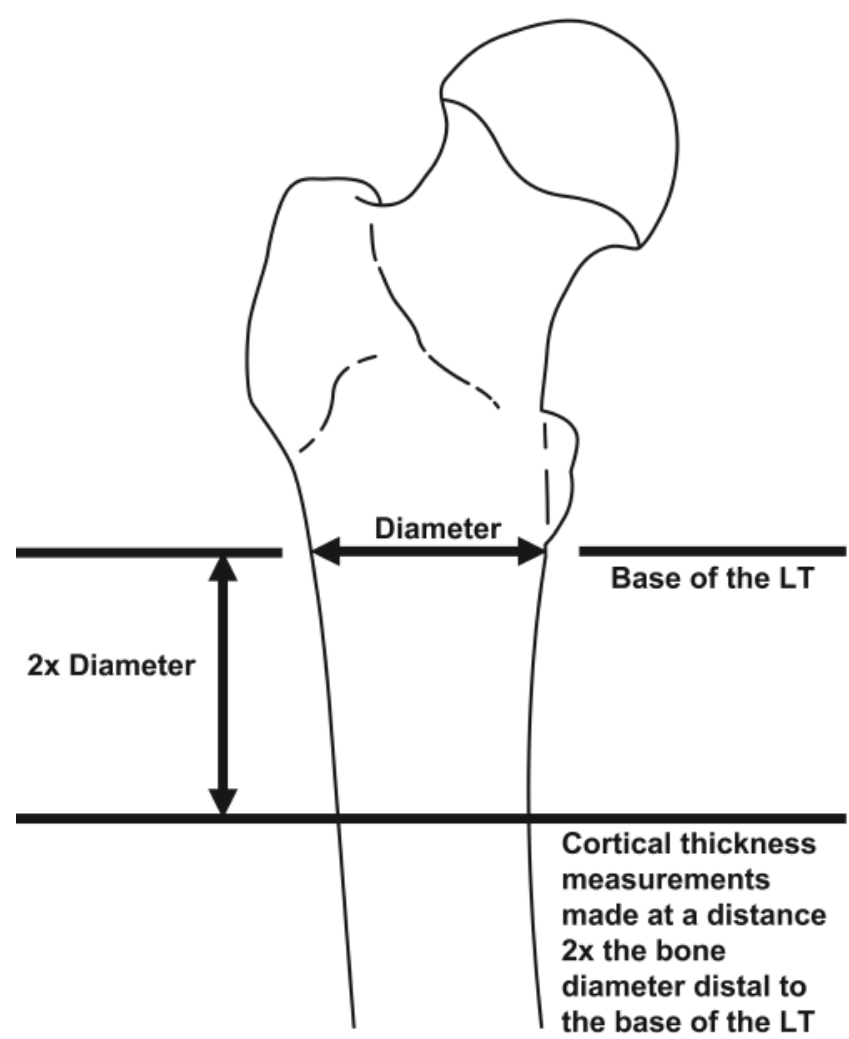

Figure 2. Representation of the femur depicting location of cortical thickness measurements. fractures: report of a task force of the American Society for Bone and Mineral Research. J Bone Miner Res 2010;25:2267-94.

3. Capeci CM, Tejwani NC. Bilateral low-energy simultaneous or sequential femoral fractures in patients on long-term alendronate therapy. J Bone Joint Surg Am 2009;91:2556-61.

4. Goddard MS, Reid KR, Johnston JC, Khanuja HS. Atraumatic bilateral femur fracture in long-term bisphosphonate use. Orthopedics 2009;32:8.

5. Lenart BA, Lorich DG, Lane JM. Atypical fractures of the femoral diaphysis in postmenopausal women taking alendronate. $\mathrm{N}$ Engl J Med 2008;358:1304-6. 